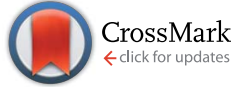

Cite this: Chem. Sci., 2017, 8, 200

Received 22nd May 2016 Accepted 9th August 2016

DOI: $10.1039 / \mathrm{c} 6 \mathrm{sc0} 02271 \mathrm{e}$

www.rsc.org/chemicalscience

\section{Selective detection of N6-methyladenine in DNA via metal ion-mediated replication and rolling circle amplification $\uparrow$}

\author{
Tingting Hong, Yushu Yuan, Tianlu Wang, Jingwei Ma, Qian Yao, Xiaoluan Hua, Yu Xia \\ and Xiang Zhou*
}

\begin{abstract}
N6-methyladenine $(6 \mathrm{~mA})$ is reported as a potential epigenetic marker in eukaryotic genomes. However, accurate identification of the location of $6 \mathrm{~mA}$ in DNA remains a challenging task. Here, we show that $\mathrm{Ag}^{+}$can selectively stabilize the $\mathrm{A}-\mathrm{C}$ mismatch and efficiently promote primer extension. In contrast, the complex of $6 \mathrm{~mA}-\mathrm{Ag}^{+}-\mathrm{C}$ is instable and therefore cannot be recognized by DNA polymerases, resulting in the termination of primer extension. Based on this finding, we successfully identified and quantified $6 \mathrm{~mA}$ at the single-base level through the analysis of gel bands of extended primers and fluorescence measurements combined with rolling circle amplification. The high selectivity and sensitivity of this strategy may provide a new platform for the efficient analysis of $6 \mathrm{~mA}$ in DNA in the future.
\end{abstract}

\section{Introduction}

Beyond the four canonical nucleobases, 5-methylcytosine $(5 \mathrm{mC})$ and N6-methyladenine $(6 \mathrm{~mA})$ have been revealed as heritable epigenetic modifications in genomic DNA. ${ }^{1}$ These modifications are associated with various biological functions that make them dominant epigenetic markers in diverse species. Unlike $5 \mathrm{mC}$, which is abundant in eukaryotes, particularly in mammals, ${ }^{2}$ the genomic distribution of $6 \mathrm{~mA}$ is initially reported to be limited to bacteria and some lower eukaryotes, and the base is found to be involved in the regulation of DNA mismatch repair, chromosome replication, cell-cycle regulation, transcription and virulence. ${ }^{3}$ However, recent discoveries have revealed potential roles of $6 \mathrm{~mA}$ in regulating gene expression in several higher eukaryotes ${ }^{4}$ or even in vertebrates ${ }^{5}$ and mammalian embryonic stem cells, ${ }^{6}$ making it a potential epigenetic marker in eukaryotic genomes.

The previous failure to detect $6 \mathrm{~mA}$ in higher eukaryotes is mainly due to the lack of available methods. Epigenetic DNA modifications do not alter the complementary base pairing, and to date, $6 \mathrm{~mA}$ has never been reported to be susceptible to chemical modifications, whereas $5 \mathrm{mC}$ can be detected via bisulfite treatment, which specifically converts cytosine into uracil and leaves $5 \mathrm{mC}$ intact, transforming the epigenetic information into sequence differences. All of these factors

College of Chemistry and Molecular Sciences, Key Laboratory of Biomedical Polymers of Ministry of Education, The Institute for Advanced Studies, Wuhan University, Wuhan, Hubei, 430072, P. R. China. E-mail: xzhou@whu.edu.cn; Fax: +86-2768756663; Tel: +86-27-68756663

$\uparrow$ Electronic supplementary information (ESI) available. See DOI: $10.1039 / \mathrm{c} 6 \mathrm{sc} 02271 \mathrm{e}$ contribute to the failure of standard hybridization-based methods for the detection of $6 \mathrm{~mA}$ in DNA. To surmount this challenge, several methods based on selective polymerase, ${ }^{7}$ sensitive restriction enzymes ${ }^{8}$ and the distinct stabilities between $\mathrm{A} / 6 \mathrm{~mA}-\mathrm{G}$ base pairs ${ }^{9}$ have been developed for the detection of $6 \mathrm{~mA}$ in DNA. However, both the selectivity and sensitivity of some methods require further improvement.

Some previous studies have successfully demonstrated the application of mismatched base pairs to the direct detection of epigenetic modifications. ${ }^{\mathbf{1 0 , 1 1}}$ In addition to the mismatches caused by non-Watson-Crick hydrogen bonding, ${ }^{12}$ metal-mediated base pairs stabilized through the formation of $\mathrm{T}-\mathrm{Hg}^{\mathrm{II}}-\mathrm{T}, \mathrm{C}-\mathrm{Ag}^{\mathrm{I}}-\mathrm{C}, \mathrm{A}-\mathrm{Ag}^{\mathrm{I}}-\mathrm{C}, \mathrm{C}-\mathrm{Ag}^{\mathrm{I}}-\mathrm{T}$ and 7DeazaA-Ag ${ }^{\mathrm{I}}-\mathrm{T}$ base pairs are also reported, ${ }^{13}$ in which metal ions are coordinated to the nitrogen donors on the rings of these nucleosides. As an alternative type of artificial base pairs, these metal ion-stabilized base pairs could also be further recognized by DNA polymerases, resulting in the incorporation of a mismatched deoxynucleotide into DNA primers through replication. However, the interactions between metal ions and epigenetically modified nucleosidecontaining base pairs ${ }^{\mathbf{1 4}}$ are not well studied, especially for N6methyladenine.

We supposed that the introduction of $6 \mathrm{~mA}$ might interfere with the formation of a metal ion-mediated mismatch because of the steric hindrance caused by the methyl group at the N6 position of adenine (Fig. 1a), which may further disturb recognition by DNA polymerases. Inspired by this potential difference between $6 \mathrm{~mA}$ and $\mathrm{A}$ in metal ion-triggered replication, we here developed a new method for the site-specific detection of adenine methylation in both ssDNA and dsDNA using $\mathrm{Ag}^{+}$. 
a)

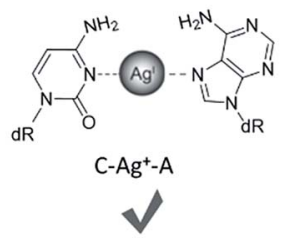

b)

$$
\begin{aligned}
& \text { 5' FAM-GCACTGTGCAGCATGTGGCAG } \\
& \text { 3'-CGTGACACGTCGTACACCGTC(N6mA/A)TA-5' }
\end{aligned}
$$

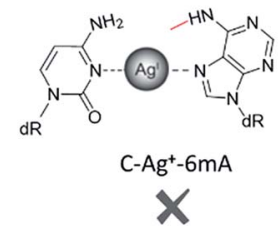

dCTP $\mathrm{Ag}^{+}$

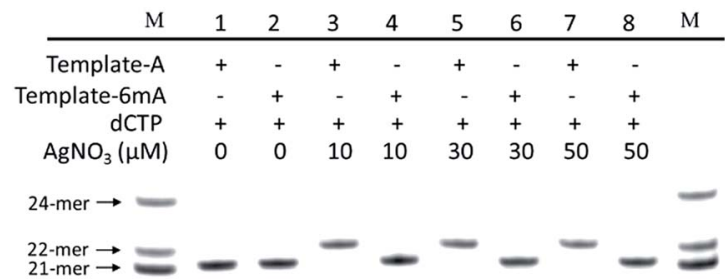

Fig. 1 Discrimination of $6 \mathrm{~mA}$ from $\mathrm{A}$ in DNA templates through $\mathrm{Ag}^{+}$ mediated replication by Klenow fragment (KF exo-) DNA polymerase (a) structure difference of $\mathrm{Ag}^{+}$-mediated base pairs between $\mathrm{A} / 6 \mathrm{~mA}$ $\mathrm{Ag}^{+}-\mathrm{C}$. (b) Sequences of $\mathrm{A} / 6 \mathrm{~mA}$-containing templates and FAMlabeled primer, and the effect of $\mathrm{Ag}^{+}$on dCMP incorporation efficiency for $A$ and $6 \mathrm{~mA}$-containing templates through single nucleotide incorporation reactions. $M$ indicates the marker for the 21-mer, 22mer and 24-mer primers.

\section{Results and discussion}

\section{Termination of primer extension caused by $6 \mathrm{~mA}$ in DNA}

We chose two 24-mer templates containing A or 6mA as DNA targets, with identical sequences except for one nucleotide difference $(\mathrm{A} / 6 \mathrm{~mA})$. To investigate the efficiencies of dCMP incorporation triggered by $\mathrm{Ag}^{+}$for $\mathrm{A} / 6 \mathrm{~mA}$-containing templates, we first performed single nucleotide incorporation reactions using Klenow fragment exo- (KF exo-) DNA polymerase.

In the absence of $\mathrm{Ag}^{+}$and dTTP, no incorporation of dCMP into primers opposite either A or 6 $\mathrm{mA}$ in DNA templates was observed (Fig. 1b Lane 1-2). With the addition of $\mathrm{Ag}^{+}$, however, the 21-mer primer was gradually extended to a 22-mer due to the formation of $\mathrm{A}^{-} \mathrm{Ag}^{+}-\mathrm{C}$ with increasing elongation time (Fig. S2 $\dagger$ ). To our delight, our data demonstrated a strikingly different result for the $6 \mathrm{~mA}$-containing template compared to the corresponding template containing $\mathrm{A}$. The elongation reaction was completely terminated at the site opposite $6 \mathrm{~mA}$ in the template, and few extended primers were detected, even with increased reaction time. These results indicated that the $6 \mathrm{~mA}-\mathrm{C}$ mismatch may not be stabilized by $\mathrm{Ag}^{+}$and further recognized by KF exo- DNA polymerase.

Next, we performed primer extensions for the A- and 6mAcontaining templates at various concentrations of $\mathrm{Ag}^{+}$(from $0.5 \mu \mathrm{M}$ to $10 \mu \mathrm{M}$, Fig. $\mathrm{S} 3, \dagger$ from $10 \mu \mathrm{M}$ to $50 \mu \mathrm{M}$, Fig. $1 \mathrm{~b}$ ), DNA Klenow fragment exo- (from 0.1 unit to 1 unit, Fig. S4 $\uparrow$ ) and dCTP (from $10 \mu \mathrm{M}$ to $100 \mu \mathrm{M}$, Fig. S5 $\dagger$ ) to explore the potential recognition of $6 \mathrm{~mA}-\mathrm{Ag}^{+}-\mathrm{C}$ by DNA polymerase. Here, the same pausing effect on elongation reaction was observed for $6 \mathrm{~mA}$ containing templates under all conditions tested, which showed the high selectivity of dCMP incorporation for the A-containing template in this $\mathrm{Ag}^{+}$-mediated replication. Thus, this significant pausing effect of $6 \mathrm{~mA}$ may provide a new platform for the site-specific detection of adenine methylation in DNA.

\section{Steric hindrance caused the instability of the $6 \mathrm{~mA}-\mathrm{Ag}^{+}-\mathrm{C}$ mismatch}

To further verify the difference between $\mathrm{A}-\mathrm{Ag}^{+}-\mathrm{C}$ and $6 \mathrm{~mA}-\mathrm{Ag}^{+}-\mathrm{C}$ mismatches in this metal ion-mediated replication, we firstly investigated the incorporation of dAMP and N6mdAMP triggered by $\mathrm{Ag}^{+}$opposite $\mathrm{C}$ residues in DNA templates (Fig. 2a). Similarly, dAMP was successfully incorporated into the primers with the aid of $\mathrm{Ag}^{+}$. As expected, considerably much fewer extended primers were detected with the addition of N6mdATP, indicating that the $6 \mathrm{~mA}-\mathrm{C}$ mismatch may not be stabilized by $\mathrm{Ag}^{+}$regardless of whether $6 \mathrm{~mA}$ served as the incoming deoxynucleotide or residue in the DNA templates. The higher incorporation efficiencies of dAMP and N6mdAMP compared with dCMP were caused by the lower energy required for the anti to syn rotation of the incoming dATP and N6mdATP. ${ }^{13 c}$

We supposed that the main reason for the instability of the $6 \mathrm{~mA}-\mathrm{Ag}^{+}-\mathrm{C}$ mismatch was the steric hindrance caused by the

a) dATP / ${ }^{6}$ mdATP $\mathrm{Ag}^{+}$ 5' FAM-GCACTGTGCAGCATGTGGCAG
3'-CGTGACACGTCGTACACCGTCCGG-5

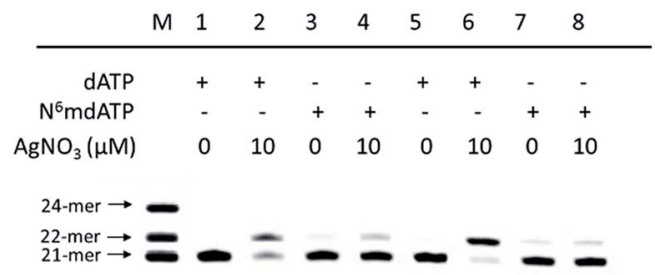

b) 3'-CGTGACACGTCGTACACCGTCATA-5

\begin{tabular}{cccccc} 
Lane & $\mathrm{M}$ & 1 & 2 & 3 & 4 \\
\hline $\mathrm{dCTP}$ & & + & + & - & - \\
$\mathrm{N}^{4} \mathrm{mdCTP}_{\mathrm{MdC}}$ & - & - & + & + \\
$\mathrm{AgNO}_{3}(\mu \mathrm{M})$ & & 0 & 10 & 0 & 10 \\
$24-\mathrm{mer} \rightarrow$ & - & & & \\
22 -mer $\rightarrow$ & - & - & -
\end{tabular}

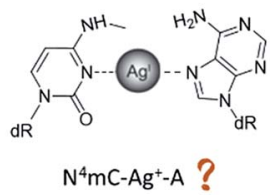

Fig. 2 (a) Incorporation efficiencies of dAMP and N6mdAMP opposite $C$ residues in DNA templates for different incubation times in the absence or presence of $\mathrm{Ag}^{+}$. The incubation time for Lane 1-4 and Lane $5-8$ is $5 \mathrm{~min}$ and $10 \mathrm{~min}$, respectively. The 21-mer primers were completely extended into 22-mer with the addition of dATP and $\mathrm{Ag}^{+}$ after a 10 min incubation at $37^{\circ} \mathrm{C}$. Compared with the high incorporation efficiency of $\mathrm{dAMP}$, much fewer extended primers were detected with the addition of N6mdATP. (b) Incorporation efficiencies of dCMP and N4mdCMP opposite A residue in DNA templates in the absence or presence of $\mathrm{Ag}^{+}$. The reactions were conducted under the same conditions described above for $30 \mathrm{~min}$. Compared with the incorporation of dCMP, a much lower efficiency of N4mdCMP incorporation was measured. $M$ indicates the marker for the 21-mer, 22-mer and 24-mer primers. 
methyl group on the N6 position of adenine, which further resulted in the failure of recognition by DNA polymerase. To verify this potential steric effect, we removed the methyl group from $6 \mathrm{~mA}$ and added it to the $\mathrm{N} 4$ position of cytosine to see if this methyl group can still reduce the stability of the $4 \mathrm{mC}-$ $\mathrm{Ag}^{+}-\mathrm{A}$ mismatch and cause the same pausing effect in this $\mathrm{Ag}^{+}$-mediated replication. As expected, much lower incorporation efficiency was detected for N4mdCMP compared to dCMP (Fig. 2b). We concluded that the introduction of the methyl group at the N4 position of cytosine and the N6 position of adenine might block the coordination between $\mathrm{Ag}^{+}$and nitrogen donors on the rings of these nucleosides, resulting in the instabilities of $6 \mathrm{~mA}-\mathrm{Ag}^{+}-\mathrm{C}$ and $4 \mathrm{mC}-\mathrm{Ag}^{+}-\mathrm{A}$. Thus, not only N6-methyladenine (6mA) but also N4-methylcytosine $(4 \mathrm{mC})$, another important epigenetic modification in the genomic DNA of bacteria, ${ }^{15,16}$ can be identified through this metal ion-mediated replication.

By contrast, the introduction of a methyl, hydromethyl, formyl or carboxyl group at cytosine ( $5 \mathrm{mC}, 5 \mathrm{hmC}, 5 \mathrm{fC}$ and $5 \mathrm{caC}$ ) did not interfere with the formation of $\mathrm{Ag}^{+}$stabilized base pairs (Fig. S6 + ) because these modifications at the C5 position of cytosine cannot cause a similar steric-hindrance effect as $6 \mathrm{~mA}$ and $4 \mathrm{mC}$ do. We also tried to use $\mathrm{Ag}^{+}$to stabilize N1mA-C but failed to achieve the extended primer although the methyl group at the $\mathrm{N} 1$ position did not have a disturbing effect on the coordination between $\mathrm{Ag}^{+}$and nitrogen donors (Fig. S7a $\dagger$ ). We speculated that this termination may be caused by the electrostatic repulsion between $\mathrm{Ag}^{+}$and the positively charged N1mA. Nevertheless, N1mA could still be distinguished from $6 \mathrm{~mA}$ and A owing to the position of its methyl group at the Watson-Crick interface, which can stall the incorporation of $\mathrm{dTMP}^{17}$ (Fig. S7b $\dagger$ ). Thus, besides the steric-hindrance effect, electrostatic interaction should also be taken into consideration for the $\mathrm{Ag}^{+}$stabilized base pairs.

\section{Quantitative evaluation of the degree of adenine methylation}

Then, we tested whether this disparate incorporation efficiency of dCMP for A and $6 \mathrm{~mA}$ templates could be employed for the quantitative evaluation of the degree of adenine methylation. First, various ratios of $6 \mathrm{~mA}$-containing templates were mixed with their A-containing counterparts to mimic samples with diverse methylation levels. We measured the yields of extended primers under the optimized conditions described above (Fig. 3b). The extension percentage showed a linear relationship with the methylation level (Fig. 3c). This quantitative result demonstrated the successful application of this metal ionmediated replication to the quantitative evaluations of the adenine methylation level at specific sites.

\section{Metal-ion mediated replication using other series of templates, DNA polymerase and metal ions}

Furthermore, we also tested two other series of $\mathrm{A} / 6 \mathrm{~mA}$ templates, in which the last two bases were changed to GG/GC (Fig. 4), to determine whether this metal ion-mediated replication would discriminate $6 \mathrm{~mA}$ from $\mathrm{A}$ in a similar way. With the addition of $\mathrm{Ag}^{+}$and $\mathrm{dCTP}$, the primer was extended into

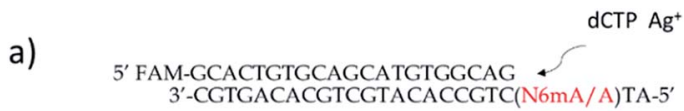

b)

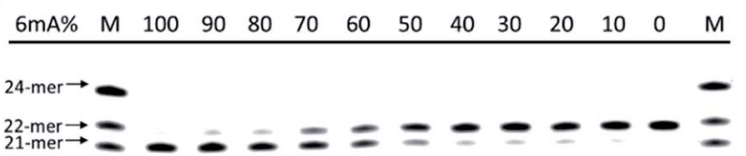

c)

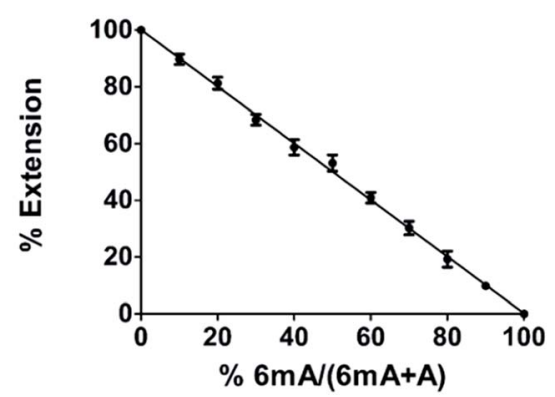

Fig. 3 Quantitative evaluation of the degree of adenine methylation in DNA through dCMP incorporation at specific sites. (a) Sequences of A/6mA-containing templates and FAM labeled primer. (b) $20 \%$ denaturing PAGE analysis of the primer extensions for the templates with various ratios of $6 \mathrm{~mA}$. (c) Linear relationship between primer extension percentages and methylation levels. Error bar, mean $\pm \operatorname{SEM}, n=3$.

a 23-mer for the A-GC template and was fully extended into a 24-mer for the A-GG template with high efficiency, indicating that the incorporation of dCMP opposite A in templates did not affect the full-length elongation. However, the KF exo-polymerase still failed to catalyze the primer extensions for the $6 \mathrm{~mA}$ containing templates.

In addition, Taq DNA polymerase was used to investigate whether this extension difference between $\mathrm{A}$ and $6 \mathrm{~mA}$ is specific to KF exo- polymerase in this metal ion-mediated replication. Fig. S8 and S9 illustrated a similar efficient extension and inhibition for the A and $6 \mathrm{~mA}$ templates, respectively, indicating the highly disparate stabilities of $\mathrm{A}-\mathrm{Ag}^{+}-\mathrm{C}$ and $6 \mathrm{~mA}-\mathrm{Ag}^{+}-\mathrm{C}$ complexes in primer extensions. $\dagger$

To investigate the effect of other metal ions on $6 \mathrm{~mA}$ discrimination using this metal ion-mediated assay, the

\begin{tabular}{|c|c|c|c|c|c|c|c|c|c|}
\hline Lane & 1 & 2 & 3 & 4 & M & 5 & 6 & 7 & 8 \\
\hline Templates & A & A & $\mathrm{mA}$ & $\mathrm{mA}$ & & A & A & $\mathrm{mA}$ & $\mathrm{mA}$ \\
\hline $\mathrm{AgNO}_{3}(\mu \mathrm{M})$ & 0 & 10 & 0 & 10 & & 0 & 10 & 0 & 10 \\
\hline \multicolumn{10}{|l|}{ 24-mer $\rightarrow$} \\
\hline \multicolumn{10}{|l|}{$\underset{21-\mathrm{mer}}{22-\mathrm{mer}} \rightarrow$} \\
\hline Lane 1-4: & \multicolumn{9}{|c|}{$\begin{array}{l}\text { 5' FAM-GCACTGTGCAGCATGTGGCAG } \\
\text { 3'-CGTGACACGTCGTACACCGTC }(\mathrm{A} / 6 \mathrm{~mA}) \mathrm{GC}-5^{\prime}\end{array}$} \\
\hline Lane 5-8: & \multicolumn{9}{|c|}{$\begin{array}{l}5^{\prime} \text { FAM-GCACTGTGCAGCATGTGGCAG } \\
\text { 3'-CGTGACACGTCGTACACCGTC }(\mathrm{A} / 6 \mathrm{~mA}) \mathrm{GG}-5^{\prime}\end{array}$} \\
\hline
\end{tabular}

Fig. 4 The discrimination of $A$ and $6 m A$ containing templates (A/6mA$\mathrm{GC}$ and $\mathrm{A} / 6 \mathrm{~mA}-\mathrm{GG}$ ) through $\mathrm{Ag}^{+}$-mediated full-length elongation. 
extension efficiencies of single-nucleotide incorporation and full-length extension using $\mathrm{A} / 6 \mathrm{~mA}-\mathrm{TA}$ and $\mathrm{A} / 6 \mathrm{~mA}-\mathrm{GG}$ templates, respectively, were both conducted in the presence of $\mathrm{Ag}^{+}, \mathrm{Li}^{+}, \mathrm{Cu}^{+}, \mathrm{Cu}^{2+}, \mathrm{Zn}^{2+}, \mathrm{Pb}^{2+}, \mathrm{Ni}^{2+}, \mathrm{Mn}^{2+}, \mathrm{Co}^{2+}, \mathrm{Fe}^{2+}, \mathrm{Fe}^{3+}$ or $\mathrm{Al}^{3+}$ (Fig. S10 and S11 $\dagger$ ). The results demonstrated that some other metal ions can catalyze primer extensions for A template to a certain degree, while the greatest extension difference between the $\mathrm{A}$ and $6 \mathrm{~mA}$ templates was observed for $\mathrm{Ag}^{+}$.

\section{Discrimination of $6 \mathrm{~mA}$ from $A$ in dsDNA templates}

As 6mA naturally exists in double-stranded DNA, we further tested whether our metal-ion mediated replication could also be applied for dsDNA. At first, we carried out the replications at $37{ }^{\circ} \mathrm{C}$ using Klenow exo-polymerase after annealing step for dsDNA templates and primer. The discrimination of $6 \mathrm{~mA}$ from A still could be achieved, but was not as significant as singlestranded DNA (Fig. S13†). To magnify the extension difference between $\mathrm{A}$ and $6 \mathrm{~mA}$, we introduced the amplification process with cycles of denaturation, annealing and replication using DNA Taq polymerase. With the increased cycles of amplification, tenfold primers were completely extended for A containing dsDNA with the aid of $\mathrm{Ag}^{+}$, leaving primers for $6 \mathrm{~mA}$ containing dsDNA almost unchanged (Fig. 5). Taking advantage of this efficient strategy, $500 \mathrm{pM} 6 \mathrm{~mA}$ can be discriminated from A in dsDNA (Fig. S14 $\dagger$ ), making it a potential assay for the detection of $6 \mathrm{~mA}$ in genomic DNA.

\section{Metal-ion mediated replication combined with RCA}

Encouraged by the high selectivity and reproducibility of our method described above, we combined this selective metal ionmediated replication with rolling circle amplification (RCA) for signal enhancement. RCA is an isothermal and exponential amplification that can generate RCA products containing thousands of tandem DNA repeats that are complementary to the circularized padlock probe. ${ }^{18,19}$ This high amplification

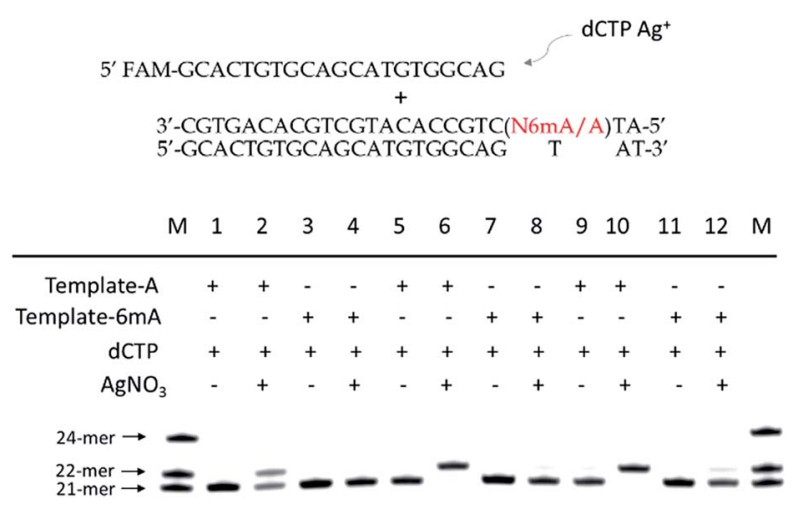

Fig. 5 Discrimination of $6 \mathrm{~mA}$ from $A$ in double-stranded DNA with the aid of $\mathrm{Ag}^{+}$using Taq DNA polymerase. With increased cycles (denaturation at $95^{\circ} \mathrm{C}$ for $15 \mathrm{~s}$, annealing and replication at $68^{\circ} \mathrm{C}$ for $10 \mathrm{~min}$ ), tenfold primers were completely extended into $22-$ mer for A-containing dsDNA templates in the presence of $\mathrm{Ag}^{+}$, while nearly no extensions were observed for $6 \mathrm{~mA}$ containing dsDNA (10 cycles for Lane 1-4, 15 cycles for Lane 5-8 and 20 cycles for Lane 9-12). efficacy has led to its widespread use in the detection of DNA, ${ }^{20}$ RNA, ${ }^{21}$ single nucleotide polymorphisms (SNPs), ${ }^{22}$ metal ions ${ }^{23}$ and proteins. ${ }^{24}$ However, this experiment here is the first reported attempt to detect $6 \mathrm{~mA}$ combined with RCA.

The $6 \mathrm{~mA}$ detection strategy based on metal ion-mediated replication and RCA is presented in Fig. 6. The padlock probe is first designed to hybridize with the target templates. For A-containing templates (A-TA and A-GG), the subsequent $\mathrm{Ag}^{+}$-promoted replication would introduce one or more nucleotides into the $3^{\prime}$ end of the padlock probe. Then, with the addition of the RCA primer, the two ends of the extended padlock probe would be brought into proximity to form a circle precursor through toehold-mediated strand displacement, initiating the ligation by T4 DNA ligase. In contrast, for $6 \mathrm{~mA}-$ containing templates (6mA-TA or $6 \mathrm{~mA}-\mathrm{GG})$, the ligation and circularization of the padlock probe were blocked even with the addition of $\mathrm{Ag}^{+}$due to incomplete complementary binding between the padlock probe and the RCA primer. The same inhibitions of ligation were also observed for A- and $6 \mathrm{~mA}-\mathrm{con}-$ taining templates without $\mathrm{Ag}^{+}$. Thus, only the A-containing templates with $\mathrm{Ag}^{+}$can trigger the RCA reaction and yield a fluorescence signal using an intercalating dye (SYBR Green I).

First, DNA templates containing A or $6 \mathrm{~mA}(\mathrm{~A} / 6 \mathrm{~mA}-\mathrm{TA})$ were characterized using this strategy. Without the addition of $\mathrm{Ag}^{+}$, both templates containing either A or $6 \mathrm{~mA}$ have much lower fluorescence signals (Fig. 7a). Once $\mathrm{Ag}^{+}$was added, however, a stable $\mathrm{A}-\mathrm{Ag}^{+}-\mathrm{C}$ complex was formed for the A-containing templates (A-TA), initiating the extension and RCA reactions. As

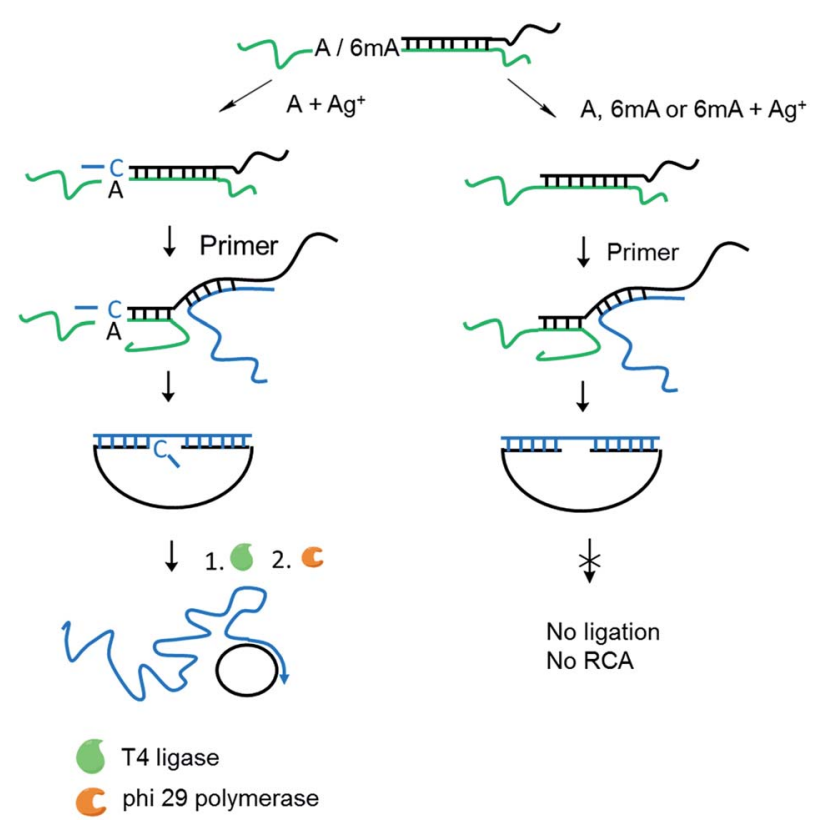

Fig. 6 Scheme of $6 \mathrm{~mA}$ detection through the RCA reaction based on metal ion-mediated replication. The green line represents templates containing A or $6 \mathrm{~mA}$. The padlock probe with a long tag (black line) acted as an extension primer here. The RCA primer (blue line) was introduced (1) to bring the two ends of the extended padlock probe together to form a circle precursor and (2) to serve as the primer in the subsequent amplification. 
a)

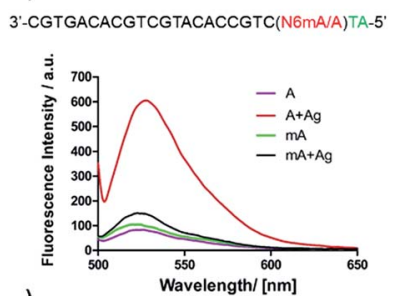

c)

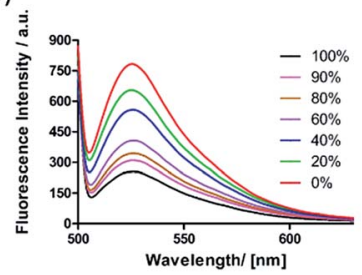

b)

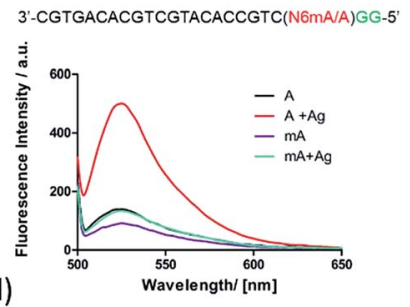

d)

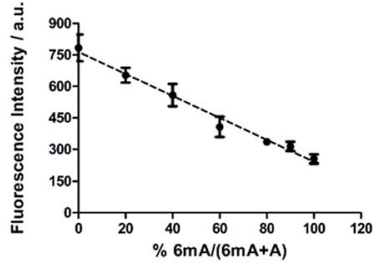

Fig. 7 Identification and quantification of $6 \mathrm{~mA}$ via metal ion-mediated replication and the RCA reaction. The discrimination of $6 \mathrm{~mA}$ from $A$ through fluorescence measurement using SYBR Green I for (a) templates $\mathrm{A} / 6 \mathrm{~mA}-\mathrm{TA}$ and (b) templates $\mathrm{A} / 6 \mathrm{~mA}-\mathrm{GG}$. Excitation wavelength: $488 \mathrm{~nm}$. (c) Fluorescence emission spectra of mixed samples with diverse proportions of methylated DNA. Here, $0 \%$ means $0 \% 6 \mathrm{~mA}$-containing templates, $100 \%$ means $100 \%$ 6mA-containing templates (d) linear relationship between fluorescence intensities and methylation levels. Error bar, mean $\pm \mathrm{SEM}, n=3$.

a result, we observed significant signals through fluorescence measurement for A-containing templates, successfully discriminating 6mA from A in DNA templates (Fig. 7a).

The determination of $6 \mathrm{~mA}$ in another series of DNA templates (A/6mA-GG) was also successfully achieved using this fluorescence strategy, demonstrating negligible differences in selectivity for these two series of DNA templates (Fig. 7b). This fluorescence strategy also worked well for the quantitative evaluation of the degree of methylation in mixed samples (Fig. 7c). As shown in Fig. 7d, the fluorescence intensity was linearly proportional to the percentage of $6 \mathrm{~mA}$. Furthermore, the products of RCA amplification were sequenced to verify the successful incorporation of dCMP in the padlock probe (Fig. S15†).

\section{Conclusions}

In summary, we have demonstrated the remarkable difference in stability between $\mathrm{A}-\mathrm{Ag}^{+}-\mathrm{C}$ and $6 \mathrm{~mA}-\mathrm{Ag}^{+}-\mathrm{C}$ due to the steric hindrance caused by the methyl group on the N6 position of adenine. As only $\mathrm{A}-\mathrm{Ag}^{+}-\mathrm{C}$ can be efficiently recognized by DNA polymerases, we successfully discriminated $6 \mathrm{~mA}$ from $\mathrm{A}$ in both ssDNA and dsDNA at the single-base level through the analysis of extended primers. Then, combined with the RCA reaction for signal enhancement, we also identified and quantified $6 \mathrm{~mA}$ through fluorescence measurements. The high selectivity and sensitivity of this strategy may make it useful in the future analysis of $6 \mathrm{~mA}$ in genomic DNA. Moreover, this metal ionmediated replication and the RCA reaction may also provide a new platform for the identification of other methylated bases, such as N4-methylcytosine $(4 \mathrm{mC})$, as disparate stabilities are also observed between $4 \mathrm{mC}-\mathrm{Ag}^{+}-\mathrm{A}$ and $\mathrm{C}-\mathrm{Ag}^{+}-\mathrm{A}$.

\section{Acknowledgements}

We thank the National Basic Research Program of China (973 Program) (2012CB720600, 2012CB720603), the National Natural Science Foundation of China (NSFC) (21432008, 81373256, and 91413109).

\section{Notes and references}

1 D. Summerer, Angew. Chem., Int. Ed., 2015, 54, 10714.

2 Z. D. Smith and A. Meissner, Nat. Rev. Genet., 2013, 14, 204. 3 (a) W. Messer and M. Noyer-Weidner, Cell, 1988, 54, 735; (b) M. G. Marinus and J. Casadesus, FEMS Microbiol. Rev., 2009, 33, 488; (c) J. Collier, H. H. McAdams and L. Shapiro, Proc. Natl. Acad. Sci. U. S. A., 2007, 104, 17111; (d) D. M. Heithoff, R. L. Sinsheimer, D. A. Low and M. J. Mahan, Science, 1999, 284, 967.

4 (a) E. L. Greer, M. A. Blanco, L. Gu, E. Sendinc, J. Liu, D. Aristizábal-Corrales, C. H. Hsu, L. Aravind, C. He and Y. Shi, Cell, 2015, 161, 868; (b) Y. Fu, G. Z. Luo, K. Chen, X. Deng, M. Yu, D. Han, Z. Hao, J. Liu, X. Lu, L. C. Doré, X. Weng, Q. Ji, L. Mets and C. He, Cell, 2015, 161, 879; (c) G. Zhang, H. Huang, D. Liu, Y. Cheng, X. Liu, W. Zhang, R. Yin, D. Zhang, P. Zhang, J. Liu, C. Li, B. Liu, Y. Luo, Y. Zhu, N. Zhang, S. He, C. He, H. Wang and D. Chen, Cell, 2015, 161, 893.

5 M. J. Koziol, C. R. Bradshaw, G. E. Allen, A. S. H. Costa, C. Frezza and J. B. Gurdon, Nat. Struct. Mol. Biol., 2015, 23, 24.

6 T. P. Wu, T. Wang, M. G. Seetin, Y. Lai, S. Zhu, K. Lin, Y. Lin, S. D. Byrum, S. G. Mackintosh, M. Zhong, A. Tackett, G. Wang, L. S. Hon, G. Fang, J. A. Swenberg and A. Z. Xiao, Nature, 2016, 532, 329.

7 S. Wang, J. Wang, X. Zhang, B. Fu, Y. Song, P. Ma, K. Gu, X. Zhou, X. Zhang, T. Tian and X. Zhou, Chem. Sci., 2016, 7,1440 .

8 (a) G. Z. Luo, M. A. Blanco, E. L. Greer, C. He and Y. Shi, Nat. Rev. Mol. Cell Biol., 2015, 16, 705; (b) G. Z. Luo, F. Wang, X. Weng, K. Chen, Z. Hao, M. Yu, X. Deng, J. Liu and C. He, Nat. Commun., 2016, 7, 11301.

9 Y. A. Chen, J. M. Obliosca, Y. L. Liu, C. Liu, M. L. Gwozdz and H. C. Yeh, J. Am. Chem. Soc., 2015, 137, 10476.

10 J. Aschenbrenner, M. Drum, H. Topal, M. Wieland and A. Marx, Angew. Chem., Int. Ed., 2014, 53, 8154.

11 J. Watzdorf, K. Leitner and A. Marx, Angew. Chem., Int. Ed., 2016, 55, 3229.

12 J. J. Voegel and S. A. Benner, J. Am. Chem. Soc., 1994, 116, 6929.

13 (a) Y. Miyake, H. Togashi, M. Tashiro, H. Yamaguchi, S. Oda, M. Kudo, Y. Tanaka, Y. Konodo, R. Sawa, T. Fujimoto, T. Machinami and A. Ono, J. Am. Chem. Soc., 2006, 128, 2172; (b) A. Ono, S. Cao, H. Togashi, M. Tashiro, T. Fujimoto, T. Machinami, S. Oda, Y. Miyake, I. Okamoto and Y. Tanaka, Chem. Commun., 2008, 4825; (c) T. Funai, Y. Miyazaki, M. Aotani, E. Yamaguchi, O. Nakagawa, S. Wada, H. Torigoe, A. Ono and H. Urata, Angew. Chem., Int. Ed., 2012, 51, 6464; (d) T. Funai, J. Nakamura, Y. Miyazaki, 
R. Kiriu, O. Nakagawa, S. Wada, A. Ono and H. Urata, Angew. Chem., 2014, 126, 6946; (e) N. Santamaría-Díaz, J. M. Méndez-Arriaga, J. M. Salas and M. A. Galindo, Angew. Chem., 2016, 128, 6278.

14 T. Tian, S. Peng, H. Xiao, Y. Long, B. Fu, X. Zhang, S. Guo, S. Wang, X. Zhou, S. Liu and X. Zhou, Chem. Commun., 2013, 49, 10085.

15 M. Ehrlich, G. G. Wilson, K. C. Kuo and C. W. Gehrke, J. Bacteriol., 1987, 169, 939.

16 M. Yu, L. Ji, D. A. Neumann, D. Chung, J. Groom, J. Westpheling, C. He and R. J. Schmitz, Nucleic Acids Res., 2015, 43, W148.

17 (a) R. Hauenschild, L. Tserovski, K. Schmid, K. Thüring, M. L. Winz, S. Sarma, K. D. Entian, L. Wacheul, D. L. J. Lafontaine, J. Anderson, J. Alfonzo, A. Hildebrandt, A. Jäschke, Y. Motorin and M. Helm, Nucleic Acids Res.,
2015, 43, 9950; (b) X. Li, X. Xiong, K. Wang, L. Wang, X. Shu, S. Ma and C. Yi, Nat. Chem. Biol., 2016, 12, 311.

18 M. M. Ali, F. Li, Z. Zhang, K. Zhang, D. K. Kang, J. A. Ankrum, X. C. Le and W. Zhao, Chem. Soc. Rev., 2014, 43, 3324.

19 W. Zhao, M. M. Ali, M. A. Brook and Y. Li, Angew. Chem., Int. Ed., 2008, 47, 6330.

20 F. Dahl, J. Banér, M. Gullberg, M. Mendel-Hartvig, U. Landegren and M. Nilsson, Proc. Natl. Acad. Sci. U. S. A., 2004, 101, 4548.

21 Y. Cheng, X. Zhang, Z. Li, X. Jiao, Y. Wang and Y. Zhang, Angew. Chem., Int. Ed., 2009, 48, 3268.

22 J. Pickering, A. Bamford, V. Godbole, J. Briggs, G. Scozzafava, P. Roe, C. Wheeler, F. Ghouze and S. Cuss, Nucleic Acids Res., 2002, 30, 60e.

23 S. Bi, B. Ji, Z. Zhang and J. J. Zhu, Chem. Sci., 2013, 4, 1858. 24 T. Konry, I. Smolina, J. M. Yarmush, D. Irimia and M. L. Yarmush, Small, 2011, 7, 395. 